\title{
POLYPEPTIDE COMPOSITION OF AN OXYGEN EVOLVING PHOTOSYSTEM II VESICLE FROM SPINACH CHLOROPLASTS
}

by

\author{
LANDIS E. A. HENRY and BIRGER LINDBERG MØLLER, \\ Department of Physiology, Carlsberg Laboratory, \\ Gamle Carlsberg Vej 10. DK-2500 Copenhagen Valby
}

Keywords: Inside-out vesicles, reversed proton pumping, cytochrome $b-559 \mathrm{HP}$, fluorescence emission spectra, chlorophyll-proteins, SDS-polyacrylamide gel electrophoresis

\begin{abstract}
An oxygen evolving photosystem II vesicle has been isolated from spinach chloroplasts by the technique of phase-partitioning. The rate of oxygen evolution was comparable to that of unfractionated thylakoids. The vesicle released protons into the ambient medium upon illumination. It emitted fluorescence strongly at $695 \mathrm{~nm}$ whereas the fluorescence at $729 \mathrm{~nm}$ was weak. The vesicle was enriched in cytochrome $b-559 \mathrm{HP}$ and contained little if any cytochrome $b-563$. The photosystem II vesicle contained four chlorophyll-proteins, namely, chlorophyll $a$-protein 2 (mol.wt. 51.000), chlorophyll $a$-protein 3 (mol.wt. 43.000), and chlorophyll $a / b$ proteins 1 and 2 (mol.wts. 30,000 and 24,000 , respectively). Also present were four polypeptides with molecular weights of $33,000,22,000,19,000$ and 18,000 .
\end{abstract}

\section{INTRODUCTION}

The thylakoid membrane in higher plants and algae contains two photosystems each with a specific reaction center plus antennae pigment system (27). Functional identification of the polypeptide components of these two systems has been attempted using a variety of electrophoretic techniques often in combination with photosynthetic mutants $(15,22,25,31,40)$. In bacteria, the assignment of polypeptides to the reaction center has been achieved by isolation and direct analysis of the components (16). In

Abbreviations: $\quad \mathrm{CF}_{1}=$ chloroplast coupling factor; $\mathrm{Chl}=$ chlorophyll; $\mathrm{Chl}-\mathrm{P}=$ chlorophyll-protein; DBMIB = 2,5-dibromo-3-methyl-6-isopropyl-p-benzoquinone; $\quad$ CCPIP $=2,6$-dichlorophenolindophenol; DCMU = 3-(3',4'-dichlorophenyl)- I, l-dimethylurea; $F=$ fluorescence emission; Hepes $=N$-2-hydroxyethylpiperazine-N'-2-ethane sulfonic acid; $\mathrm{HP}=$ high potential; $\mathrm{LP}=$ low potential: $\mathrm{Mes}=2-(N$-morpholine $)$ ethane sulfonic acid; Mops = morpholinepropane sulfonic acid; PS = photosystem; SDS-PAGE = sodium dodecyl sulfate-polyacrylamide gel electrophoresis; $\quad$ Tricine $=N$-(2-hydroxy-1,1-bis(hydroxymethyl)ethyl)glycine; Tris = tris $-($ hydroxymethyl)-aminomethane. 
higher plant systems such an approach has made possible the assignment of a small number of polypeptides to photosystem I $(13,22,34)$. Hitherto, a sufficiently purified oxygen evolving photosystem II particle has not been available to make a similar assignment of polypeptides to this photosystem.

P.-A. Albertsson, H.-E. Åkerlund and B. ANDERSSON (1-7) prepared inside-out vesicles enriched in photosystem II from chloroplast grana. After disrupting and resealing of the grana membranes (28) such inside-out vesicles preferentially partition into a dextran-rich polymer phase. We have optimised the purification of these photosystem II containing and oxygen evolving inside-out vesicles from spinach for a minimum content of thylakoid polypeptides.

\section{MATERIALS AND METHODS}

\subsection{Plant material and chloroplast isolation}

Spinacia oleracea $L$. was obtained from the local market. Intact chloroplasts were isolated in a medium composed of $1.0 \mathrm{~mm}$-sodium isoascorbate, $0.35 \mathrm{M}$-sorbitol, $10 \mathrm{~mm}-\mathrm{MgCl}_{2}$ and $50 \mathrm{~mm}$ morpholinepropane sulphonic acid (Mops), $\mathrm{pH}$ 7.5 (21). The chloroplasts were osmotically lysed by a 10 -fold dilution with the above medium containing no sorbitol and the lamellar systems washed by 2 cycles of centrifugation $(5 \mathrm{~min}$ $12,000 \mathrm{~g}$ ) and resuspension in the same medium.

\subsection{Preparation of PS II vesicles}

Mechanical disruption of the photosynthetic lamellae and subsequent fractionation was carried out with an aqueous two-phase (dextran/ polyethylene glycol) polymer system according to Albertsson (2) with some modifications. Lamellar systems (1.25 mg chlorophyll. $\left.\mathrm{ml}^{-1}\right)$ in $50 \mathrm{~mm}$-Mops (pH 7.5), 1 $\mathrm{mm}$-isoascorbate and $10 \mathrm{mM}^{-} \mathrm{MgCl}_{2}$ were disrupted in a French Pressure Cell press (American Instrument Company, Maryland, USA) (flow rate $5 \mathrm{ml} \cdot \mathrm{min}^{-1}$ ) at a pressure of $3,400 \mathrm{lb} \cdot \mathrm{in}^{-2}$. The pressate was centrifuged at $40,000 \mathrm{~g}$ for $30 \mathrm{~min}$ and the pellet resuspended in $10 \mathrm{~mm}$-sodium phosphate $(\mathrm{pH}$ 7.4), $5 \mathrm{~mm}-\mathrm{NaCl}$ and $100 \mathrm{~mm}$-sucrose to facilitate destacking. Two additional French press treatments of $2,800 \mathrm{lb} \cdot \mathrm{in}^{-2}$ ensured vesicles of uniform size. The concentration of both poly- mers during the phase partitioning experiments was $5.95 \%$. The membrane vesicles collected by ultracentrifugation were resuspended in $40 \mathrm{~mm}$ $\mathrm{NaCl}$. All operations were carried out at $2.5^{\circ} \mathrm{C}$ and all experiments done with freshly prepared vesicles.

\subsection{Photochemical assays}

Spectrophotometric determinations were carried out with an Aminco DW-2a spectrophotometer operating in either the split-beam or dualwavelength mode. The samples were irradiated with saturating red light. DCPIP photoreduction was determined as in (21), except that the rate of decrease in absorbance was measured at $550 \mathrm{~nm}$. Photoreduction of methyl viologen was determined by coupling the reaction to the light dependent generation of a proton gradient. This was followed by the use of the $\mathrm{pH}$ indicator phenol red with the spectrophotometer operating in the dual-wavelength mode (33).

Oxygen evolution assays were carried out polarographically using a Rank Brothers oxygen electrode (Rank Bros., Bottisham, Cambridge, U.K.). This was done with 3 different electron acceptors in media composed of (a) $0.35 \mathrm{M}$ sorbitol, 2mм-EDTA, 5mм- $\mathrm{MgCl}_{2}$, 50mм- $\mathrm{N}-2$ hydroxyethylpiperazine- $N$ '-2-ethane sulphonic acid (Hepes) pH 7.6, 2,5mm-potassium ferricyanide. (b) $50 \mathrm{~mm}-2-(\mathrm{N}$-morpholineethane sulphonic acid (Mes), pH 6.6, 25mm- $\mathrm{NaCl}, 0.2 \mathrm{~mm}$ -

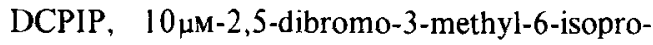
pyl-p-benzoquinone (DBMIB) (c) 50mm-sodium phosphate, $\mathrm{pH}$ 7.0, 0.5mm-phenyl-p-benzoquinone. Photoreduction of methyl viologen was determined by measuring oxygen uptake in a medium composed of $50 \mathrm{~mm}$-Tricine, $\mathrm{pH} 8.4$, $35 \mathrm{~mm}-\mathrm{NaCl}, 2 \mathrm{~mm}-\mathrm{NaN}_{3}, 10 \mu \mathrm{m}-\mathrm{DCMU}, 4 \mathrm{~mm}-$

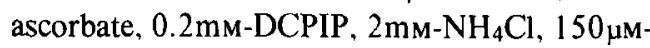
methyl viologen.

Simultaneous measurements of proton gradient formation and oxygen evolution were carried out in a Rank Brothers oxygen electrode fitted with a GK 2322C Radiometer Micro combination electrode (Radiometer, Copenhagen, Denmark) in the inner compartment. The combination electrode was inserted through the center plug using air-tight 0 -ring fittings. The $\mathrm{pH}$ changes were monitored using a Radiometer PHM 62 standard $\mathrm{pH}$ meter and recorded with a 
Servogor 220 Recorder using a full scale sensitivity of $50 \mathrm{mV}$ for the membrane vesicles and $200 \mathrm{mV}$ for the unfractionated thylakoids. The L 409 polarizing adapter and the buffer adjustment screw of the $\mathrm{pH}$-meter was used to adjust the electrical zero. Saturating white light was provided by a Schott KL 150B light source (Schott, Mainz, F.R.G.) equipped with an $8 \mathrm{~mm}$ fiber optic system. The instrument was calibrated with known amounts of $\mathrm{NaOH}$ and $\mathrm{HCl}$.

All photochemical assays were carried out at $20{ }^{\circ} \mathrm{C}$ and the chlorophyll concentration was $25 \mu \mathrm{g}$ chlorophyll $\mathrm{ml}^{-1}$ unless otherwise specified.

\subsection{Absorption and fluorescence emission spectra}

Absorption spectra were recorded at room temperature using an Aminco DW-2a spectrophotometer. Fluorescence emissions were recorded at $77 \mathrm{~K}$ using a fibre optic system (41) with samples placed on filter paper discs.

\subsection{Electrophoretic analyses}

Samples were prepared for electrophoresis as earlier described $(15,31)$. Electrophoretic analyses were carried out in a SDS system at $4{ }^{\circ} \mathrm{C}$ using a $6 \%$ stacking gel and a 10-15\% linear polyacrylamide gradient separation gel (31). After electrophoretic separation the gels were stained for heme-associated peroxidase activity $(24,44)$ and/or protein using Coomassie Blue R250.

\subsection{Cytochrome determination}

Cytochromes were determined from their chemically reduced minus oxidised difference spectra $(520-580 \mathrm{~nm})$ by the use of an Aminco DW-2a spectrophotometer. From these difference spectra, the cytochromes were quantified based on a millimolar extinction coefficient of 20 $\mathrm{cm}^{2} \cdot$ mole $^{-1}$.

\subsubsection{Determination of cytochrome $f$ and $b-559 H P$}

These measurements were carried out essentially as described by Bendall et al., (12). The samples were suspended in 50mm-Mes, $\mathrm{pH} 6.0$ at a chlorophyll concentration of $100 \mu \mathrm{g} \cdot \mathrm{ml}^{-1}$. The redox mediators potassium ferricyanide and hydroquinone were added separately to identical samples to give a final concentration of $1.25 \mathrm{~mm}$. The difference spectrum was recorded after equilibration. The height of the peak at $559 \mathrm{~nm}$ was taken above a line drawn through the minima at either side of the peak and was corrected for any non-linearity in the baseline. Triton X-100 (1\% final concentration) was added to both cuvettes. This converted the cytochrome $b-559 \mathrm{HP}$ into a form with a lower potential, no longer reducible by hydroquinone (38). The difference spectrum was again measured and now reflects the presence of cytochrome $f$ only. Quantification was carried out using the peak height at $554 \mathrm{~nm}$. The peak height at $559 \mathrm{~nm}$ was measured in order to subtract the contribution of cytochrome $f$ from the cytochrome $b-559 \mathrm{HP}$ value measured before the Triton addition.

\subsubsection{Determination of cytochrome $b-563$ and $b-559 L P$}

The procedure of RICH and BENDALL was used (38). Each sample was suspended in a medium containing $50 \mathrm{~mm}-\mathrm{Mes}, \mathrm{pH} \quad 6.0$, and $1 \mathrm{~mm}$ hydroquinone. Catalase (400 Units $\mathrm{ml}^{-1}$, Mann Research Laboratories) was included in the reaction mixture to remove $\mathrm{H}_{2} \mathrm{O}_{2}$ formed during the reaction of dithionite with oxygen. Under these conditions cytochrome $f$ and $b-559 \mathrm{HP}$ will be fully reduced. Menadiol freshly prepared as described in (37) was added to the sample cuvette to a final concentration of $1 \mathrm{~mm}$. The difference spectrum was recorded and the absorption maximum at $559 \mathrm{~nm}$ reflects the preferential reduction of cytochrome $b$-559LP. A few crystals of solid dithionite were then added to the measuring cuvette whereas the reference cuvette was made $1 \mathrm{~mm}$ with respect to menadiol. The difference spectrum was recorded after equilibration and reflects the specific reduction of cytochrome $b-563$.

\subsection{Analytical procedures}

Chlorophylls were determined in $80 \%$ acetone and quantified according to ARNON (11). 
Protein determinations were carried out with the Folin method as modified in (36) with crystalline bovine serum albumin as standard.

\section{RESULTS}

Phase partitioning of the membrane fractions was tested at a series of polymer concentrations ranging from $5.4-6.6 \%$. The chlorophyll content, polypeptide composition and photochemical activities of material partitioning to the polyethylene glycol-rich upper phase and to the dextranrich lower phase were analysed. Optimal purity of the PS II vesicles was obtained using a twophase system composed of $5.95 \%$ of each polymer.

Table I shows the composition and photochemical activities of the fractions at various stages of the purification procedure. The fraction partitioning to the dextran-rich lower phase was markedly depleted in PS I and enriched in PS II activity corresponding to 9 and $215 \%$, respectively, of the activities seen in the polyethylene glycol-rich upper phase. The total recovery of PS II activity was $38 \%$. The yield of PS II membrane vesicles was approximately $8 \%$ on a chlorophyll basis and $4.5 \%$ on a protein basis. The PS II vesicles had a chlorophyll $a / b$ ratio of
2.1 and protein/chlorophyll ratio of $4.3 \%$ compared to 3.0 and 7.3 , respectively, for the unfractionated membranes.

\subsection{Spectral analyses}

The absorption spectrum of the PS II vesicles at room temperature (Figure 1) reveals an enrichment in chlorophyll $b$ while the stroma lamellae $(40,000 \mathrm{~g}$ supernatant) are virtually free of chlorophyll $b$. The spectrum obtained with material partitioning to the polyethylene glycolrich upper phase was similar to that obtained with the chloroplast. All the fractions have a chlorophyll $a$ red absorption maximum at $680-$ $681 \mathrm{~nm}$.

The low temperature $(77 \mathrm{~K})$ fluorescence emission spectra of the different fractions obtained during the preparation of the PS II membrane vesicles are shown in Figure 2. Samples of equal chlorophyll concentrations were used to allow direct comparison of the fluorescence yields. It should be noted that the spectrum of the stroma lamellae was recorded after a two-fold expansion as compared with the other samples. The spectrum of chloroplasts showed the characteristic emission peaks at 685,695 and $730-740 \mathrm{~nm}$. These peaks have

\section{Table I}

Characteristics and yield of the fractions obtained during purification of the photosystem II vesicles.

\begin{tabular}{|c|c|c|c|c|c|c|}
\hline \multirow[t]{2}{*}{ Fraction } & \multirow{2}{*}{$\frac{\text { Chlorophyll }}{(\mathrm{mg})}$} & \multirow{2}{*}{$\frac{\text { Protein }}{(\mathrm{mg})}$} & \multirow[t]{2}{*}{$\begin{array}{c}\text { Chlorophyll } \\
a / b\end{array}$} & \multirow[t]{2}{*}{$\begin{array}{l}\text { Protein/ } \\
\text { Chlorophyll }\end{array}$} & \multicolumn{2}{|c|}{ Specific Activities } \\
\hline & & & & & $\mu$ moles acceptor & or reduced \\
\hline & & & & & $\underset{\text { methyl viologen }}{\text { Asc/DCPIP } \rightarrow} \underset{\text { (PS activity) }}{\mathrm{H}_{2}}$ & $\begin{array}{l}\mathrm{H}_{2} \mathrm{O} \rightarrow \text { DCPIP } \\
\text { (PS II activity) }\end{array}$ \\
\hline Lamellar systems & 28.2 & 205 & 2.98 & 7.26 & 124 & 59.2 \\
\hline Grana & 26 & 162 & 2.53 & 6.25 & 117 & 21.4 \\
\hline Stroma lamellae & 3.5 & 22 & $>7$ & 6.36 & 228 & 0.0 \\
\hline Disrupted grana & 25.2 & 137 & - & 5.40 & 124 & 10.7 \\
\hline $\begin{array}{l}\text { Vesicles in poly- } \\
\text { ethylene glycol phase }\end{array}$ & 5.8 & 32 & 3.48 & 5.47 & 153 & 10.7 \\
\hline $\begin{array}{l}\text { PS II vesicles in } \\
\text { dextran phase }\end{array}$ & 2.2 & 9.3 & 2.10 & 4.29 & 14 & 23 \\
\hline
\end{tabular}




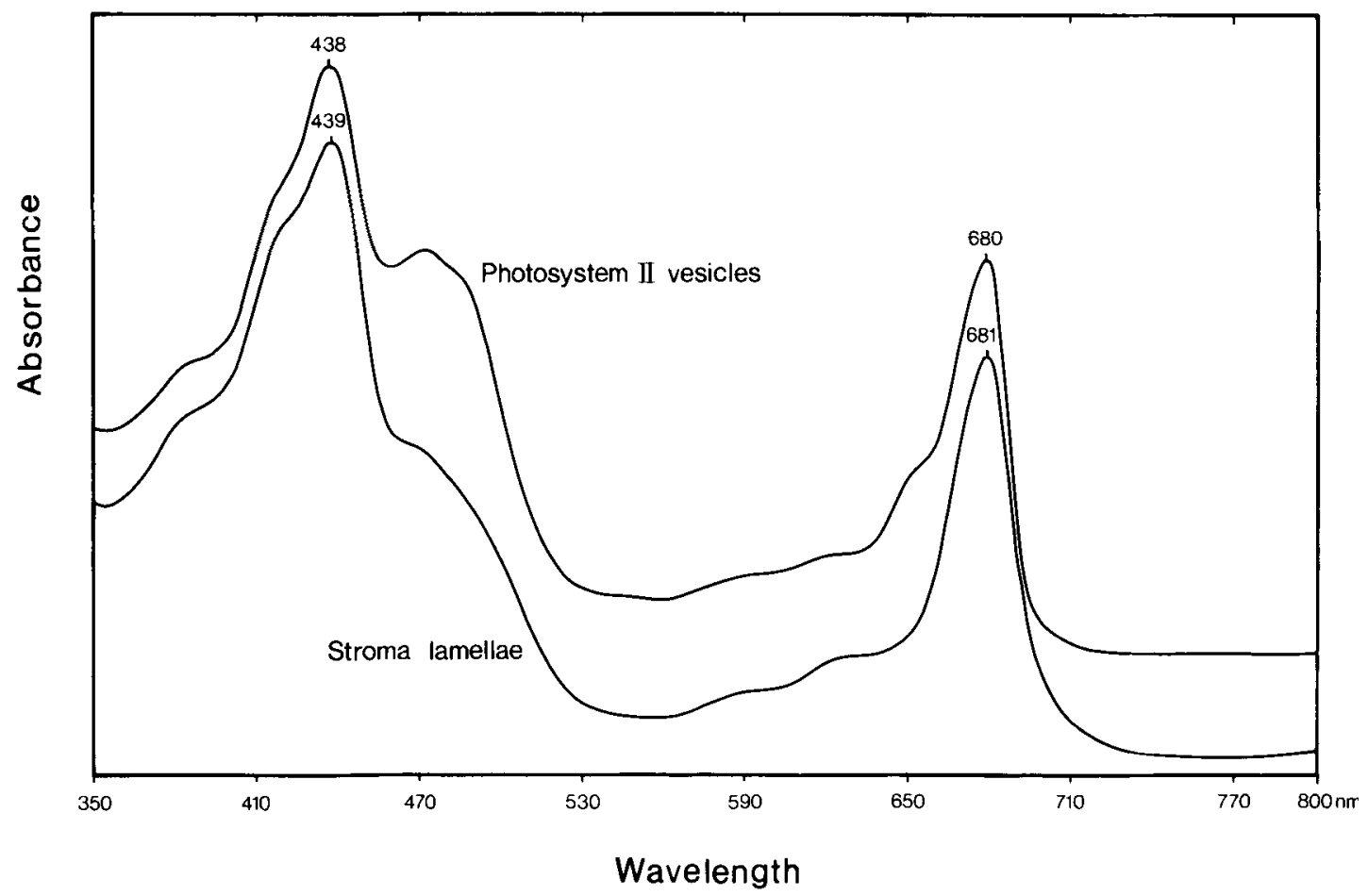

Figure 1. Absorption spectra of photosystem II vesicles and of stroma lamellae.

been attributed to emission arising from three principal types of antennae chlorophylls in chloroplasts, namely those of the light-harvesting chlorophyll $a / b$-protein 2 , the antennae pigments of PS II and of PS I, respectively (14). The spectral features of the membrane vesicles which partitioned to the polyethylene glycol-rich upper phase are very similar to those of the chloroplasts. In contrast, the emission spectrum of the PS II vesicles had the predominant peak at $695 \mathrm{~nm}$ and a $F_{730 / 695}$ ratio of 0.66 compared to that of 2.8 in the chloroplasts. The emission spectrum of the stroma lamellae shows a single peak at $731 \mathrm{~nm}$.

Thus, fluorescence species distinguishable in the composite spectrum of the thylakoids have been separated during the preparation of the stroma lamellae and the PS II vesicles. This has been accomplished without a blue shift in the $F_{695}$ maximum, as is frequently observed (39) with other methods of fractionation. This suggests that the state of the chlorophylls in the preparation has remained unaltered.

\subsection{Photochemical activities}

The PS II vesicles exhibited high rates of oxygen evolution with $\mathrm{H}_{2} \mathrm{O}$ as the electron donor and using phenyl-p-benzoquinone, DCPIP or ferricyanide as terminal electron acceptors (Table II). The measured rates of activities were comparable with those obtained using chloroplasts. This suggests that components involved in these reactions were not depleted and/or inactivated during the isolation procedure. The activities were DCMU sensitive and could be inhibited by Tris washing $(0.8 \mathrm{~m}, \mathrm{pH} 8.8)$. The latter treatment is known to inhibit electron transport on the oxidising side of PS II (18).

The use of the lipophilic electron acceptor phenyl- $p$-benzoquinone ensured that the electron transport was entirely attributable to PS II. This was further substantiated by the use of the plastoquinone analogue DBMIB during the photoreduction of DCPIP. Although ferricyanide is often used as a Hill oxidant it has previously been shown capable of accepting electrons from both photosystems under appropriate conditions (45). 
L. E. A. Henry \& B. L. Møl.ler: An oxygen evolving photosystem II vesicle

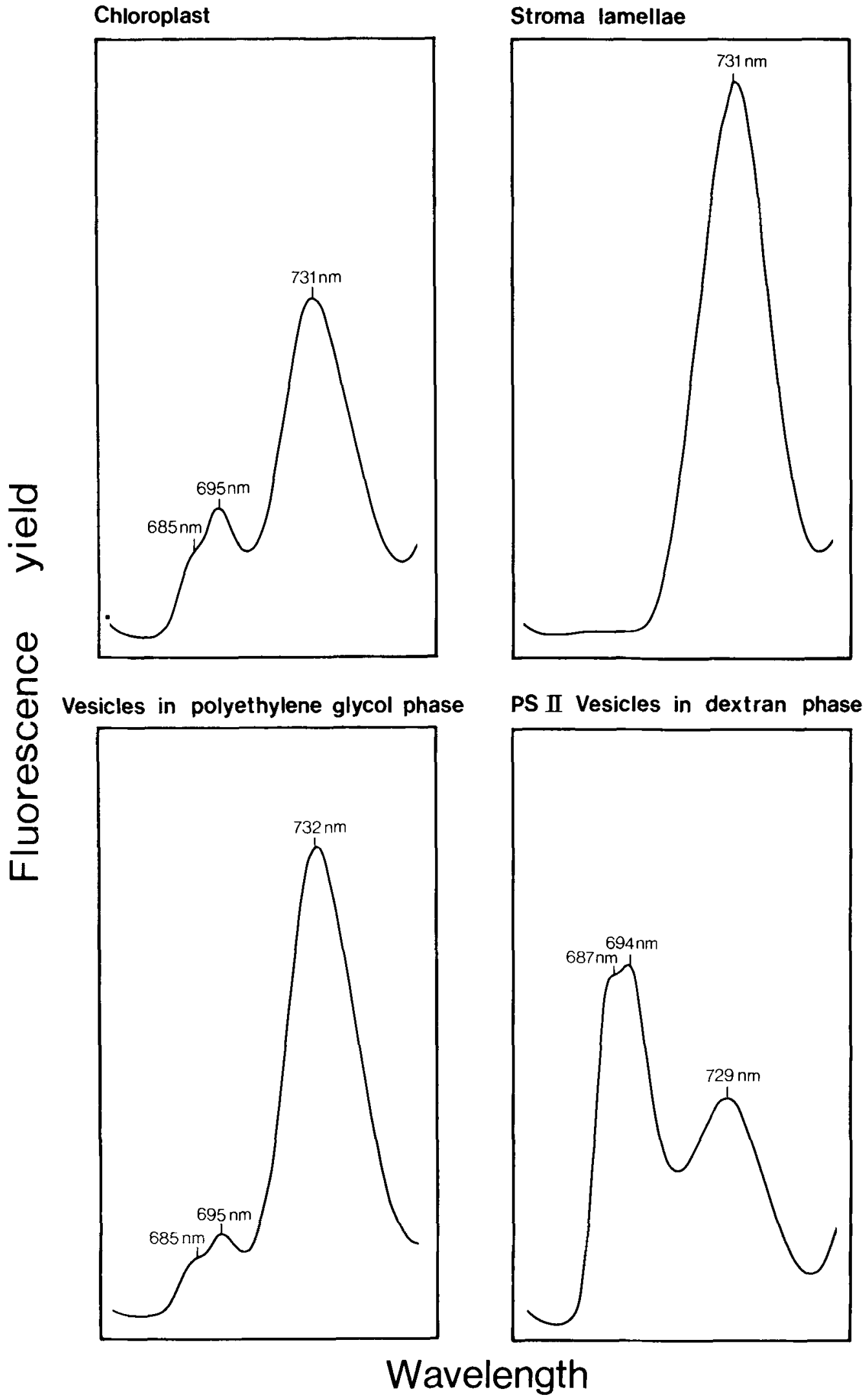


Figure 2. Low temperature fluorescence emission spectra of fractions obtained during preparation of the photosystem II vesicle.

\section{Table II}

Oxygen evolution of PS II vesicles compared with other membrane fractions using different electron acceptors ( $\mu$ moles $\mathrm{O}_{2} \cdot \mathrm{mg}^{-1}$ chlorophyll $\cdot \mathrm{hr}^{-1}$ ).

\begin{tabular}{lcrrrr}
\hline Assay & $\begin{array}{c}\text { PS II } \\
\text { Vesicles in } \\
\text { dextran phase }\end{array}$ & Chloroplasts & $\begin{array}{c}\text { Vesicles in } \\
\text { polyethylene glycol }\end{array}$ & $\begin{array}{c}\text { Stroma } \\
\text { lamellae }\end{array}$ \\
\hline $\begin{array}{l}\mathrm{H}_{2} \mathrm{O} \rightarrow \text { phenyl- } \\
p \text {-benzoquinone }\end{array}$ & $70-76$ & $40-56$ & $20-34.5$ & $0-2$ \\
$\mathrm{H}_{2} \mathrm{O} \rightarrow$ DCPIP & $73-85$ & $102-137$ & $48-60$ & $0-0$ \\
$\mathrm{H}_{2} \mathrm{O} \rightarrow$ ferricyanide & $160-258$ & $119-148$ & $137-171$ & $0-0$ \\
$\mathrm{H}_{2} \mathrm{O} \rightarrow$ methyl vilogen & & & & & \\
$\mu$ moles $\mathrm{H}^{+}$mg chlorophyll-1 & $0-0$ & $0.31-0.47$ & $0.07-0.16$ & $0-0$ \\
\hline
\end{tabular}

With methyl viologen as the electron acceptor only the chloroplast and membrane vesicles partitioning to the polyethylene glycol-rich upper phase were active. This suggests a more complete electron transport chain in these fractions. In the reactions characteristic of PS II the measured rates of activities seen in the polyethylene glycol-rich upper phase were appreciably lower than the rates seen in the PS II vesicles. As expected, the stroma lamellae were essentially devoid of activity in these determinations.

Figure 3 shows the extent and direction of proton movement in the membrane vesicles obtained after phase-partitioning. The vesicles partitioning to the polyethylene glycol-rich upper phase showed an alkalinisation of the medium upon illumination. This photochemical activity is characteristic of broken chloroplasts (35) and suggests that the side orientations of these membrane preparations are comparable. However, the extent of this proton flux was appreciably lower in the membrane vesicles obtained after phase partitioning, amounting to 7.9 nmoles $\mathrm{H}^{+} \cdot \mathrm{mg}^{-1}$ chlorophyll as compared with

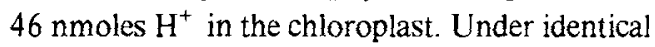
conditions the PS II vesicles showed a net proton extrusion upon illumination corresponding to 6.9 nmoles $\mathrm{H}^{+} \cdot \mathrm{mg}^{-1}$ chlorophyll. This indicates that the PS II vesicles are of opposite sidedness to the original thylakoid membrane $(4,5)$. Because of the time dependent loss in photochemical activities all fractions were measured after completion of the PS II vesicle preparation procedure. The samples were stored at $0-4{ }^{\circ} \mathrm{C}$ in the dark during this time.

\subsection{Cytochromes}

Table III lists the cytochrome composition of the PS II vesicles, the membrane vesicles partitioning to the polyethylene glycol-rich upper phase and the unfractionated membrane. The four cytochromes generally thought to be involved in plant photosynthesis, cytochrome $b$-559HP, $b$-559LP, $b$-563 and cytochrome $f(17)$ were present in the fractions albeit in varying amounts. The PS II vesicles were enriched in cytochrome $b-559 \mathrm{HP}$ relative to the other membrane samples and showed an 8-fold increase compared to the membrane vesicles partitioning to the polyethylene glycol-rich upper phase. In contrast, the PS II vesicles were extensively depleted of cytochrome $b-563$ and cytochrome $f$. An enrichment of cytochrome $b$-559LP was found in the polyethylene glycolphase associated membrane vesicles. 
L. E. A. Henry \& B. L. Møller: An oxygen evolving photosystem Il vesicle

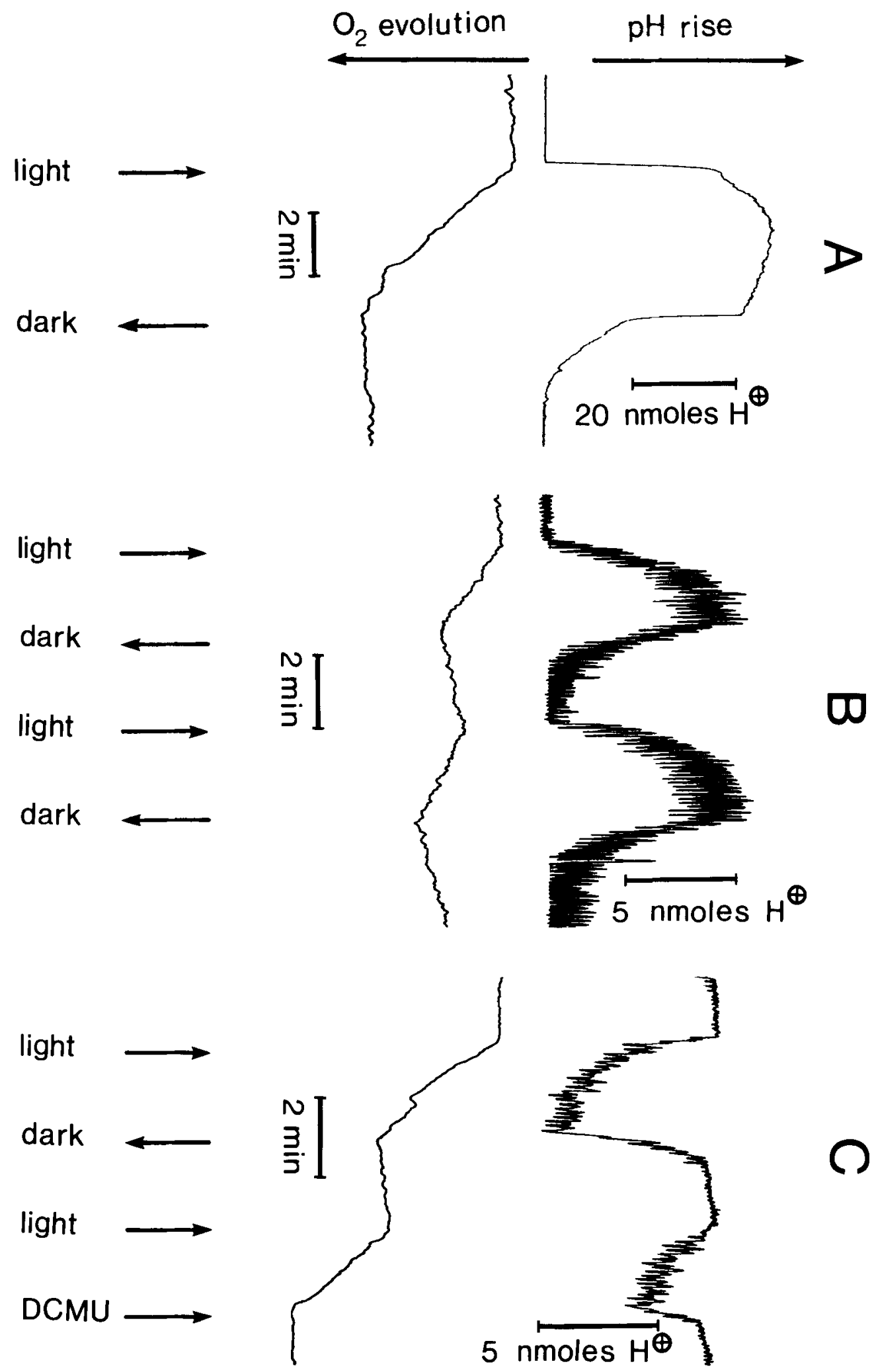

Figure 3. Proton gradient formation and oxygen evolution observed upon illumination of thylakoids (A), vesicles partitioning to the polyethylene glycol phase (B) and photosystem II vesicles (C). 


\section{Table III}

Cytochrome content in PS II vesicles compared with two other membrane fractions (moles-1000 moles chlorophyll-1).

\begin{tabular}{lcccc}
\hline Fraction & Cytochrome $b$-559HP & Cytochrome $b$-559LP & Cytochrome $b$-563 & Cytochrome $f$ \\
\hline $\begin{array}{l}\text { Lamellar systems } \\
\begin{array}{l}\text { Vesicles in polyethylene } \\
\text { glycol phase }\end{array}\end{array}$ & 1.74 & 1.27 & 3.69 & 1.21 \\
$\begin{array}{l}\text { PS II vesicles in } \\
\text { dextran phase }\end{array}$ & 0.3 & 3.22 & 4.18 & 1.25 \\
\hline
\end{tabular}

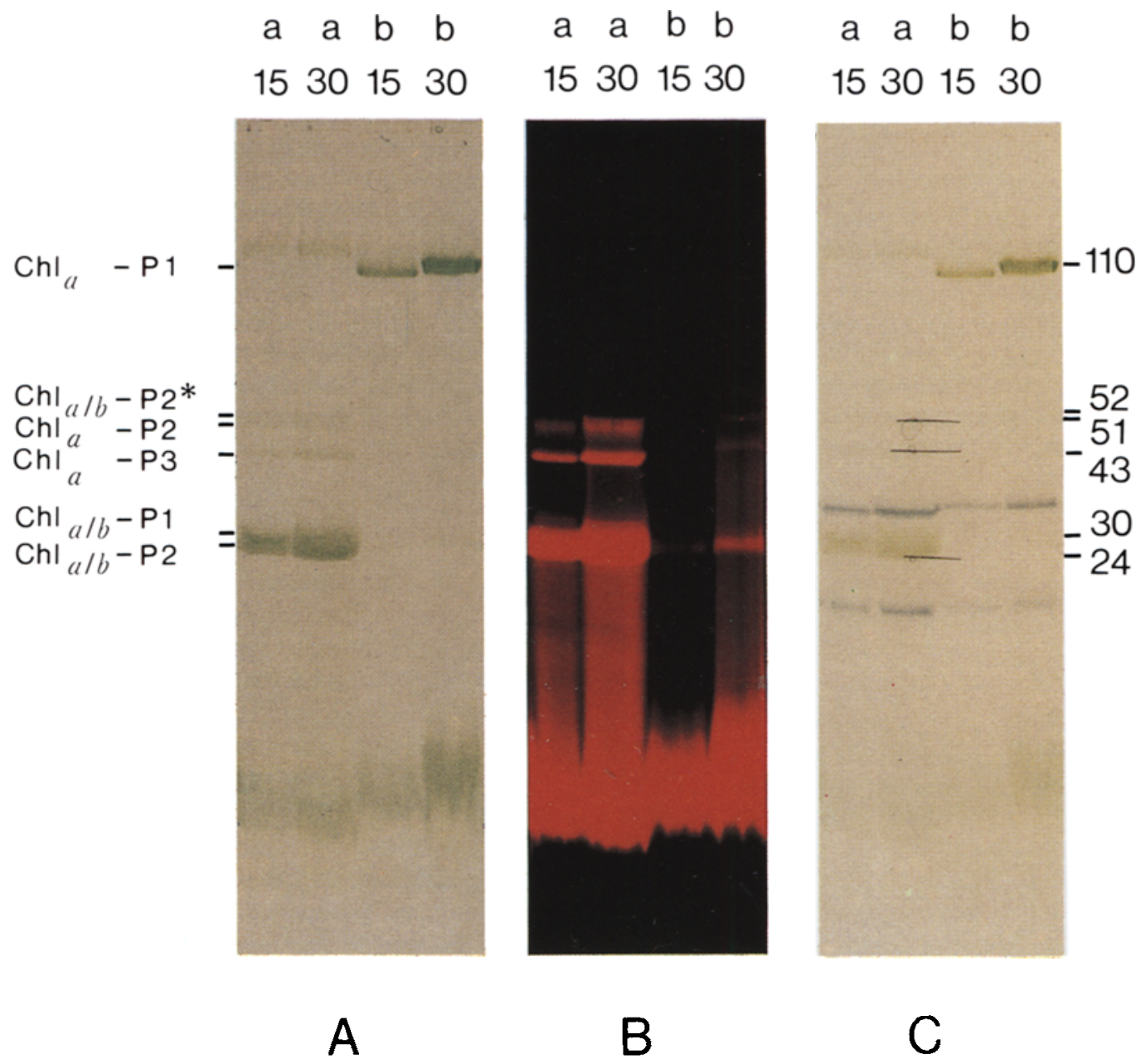

Figure 4. SDS-polyacrylamide gel electrophoresis of photosystem II vesicles (a) and vesicles partitioning to the polyethylene glycol phase (b) A: chlorophyll-proteins, B: chlorophyll-proteins as detected by their fluorescence emission (31), C: chlorophyll-proteins and bands stained for heme-associated peroxidase activity using tetramethylbenzidine (44).

The separation was carried out at $4{ }^{\circ} \mathrm{C}$ on an $11-15 \%$ SDS-polyacrylamide gradient gel. The amount of chlorophyll applied to each slot is indicated ( $\mu \mathrm{g}$ ). Three steel rods were inserted (track a-30) to mark the positions of the chlorophyll-proteins. The nomenclature system used for the chlorophyll-proteins is defined in (31). 


\subsection{Electrophoretic analyses}

Sodium dodecylsulfate polyacrylamide gel electrophoresis was used to investigate the polypeptide composition of the different membrane fractions obtained in the purification of the PS II vesicles. In the unstained gel the thylakoid preparation routinely showed three principal chlorophyll-containing bands. Identification of these bands was based on a comparison of their electrophoretic mobilities and fluorescence patterns with chlorophyll-proteins identified in barley (31). Like the thylakoids the membrane vesicles partitioning to the polyethylene glycolrich upper phase showed $\mathrm{Chl}_{a}-\mathrm{P} 1, \mathrm{Ch}_{a / b}-\mathrm{P} 2$ and free pigments in comparable amounts. In contrast, the PS II vesicles contained no (or very little) $\mathrm{Chl}_{a}-\mathrm{Pl}$ (Figure 4A). This chlorophyll protein has a low fluorescence yield (Figure 4B) and is thought to be associated with the reaction center of PS I. An enrichment of $\mathrm{Chl}_{a / b}-\mathrm{P} 2$ was seen in the PS II vesicles (Figure 4).

Additional chlorophyll-proteins were also observed after the electrophoretic separation, namely: $\mathrm{Ch}_{a / b}-\mathrm{P} 1, \mathrm{Chl}_{a / b}-\mathrm{P} 2^{*}, \mathrm{Chl}_{a}-\mathrm{P} 2$ and $\mathrm{Chl}_{a}-\mathrm{P} 3$ (Figure 4A and 4B). Although the intensities of these bands decreased upon prolonged electrophoresis their relative amounts varied in the different membrane fractions. The PS II vesicles were highly enriched in all these four chlorophyll proteins whereas these bands were markedly depleted or absent from the stroma lamellae. These data are consistent with previous studies implying an involvement of $\mathrm{Ch}_{a}-\mathrm{P} 2$ and $-\mathrm{P} 3$ in photosystem II $(22,31)$.

A comparison of the polypeptide composition of membrane vesicles obtained by phase partitioning shows distinct differences (Figures 5 and 6). The PS II vesicles contained eight polypeptides with apparent molecular weights of 51,000 . $43,000,33,000,30,000,24,000,22,000$, 19,000 and 18,000 . In contrast, the membrane vesicles partitioning to the top phase displayed a more complex polypeptide pattern.

Figure 5. Polypeptide composition of vesicles partitioning to the polyethylene glycol-rich top phase (a) and of the photosystem II vesicles which partitions to the dextran-rich bottom phase (b).

Electrophoretic conditions as indicated in legend to Figure 4. The same amount of chlorophyll $(20 \mu \mathrm{g})$ is applied to each slot.

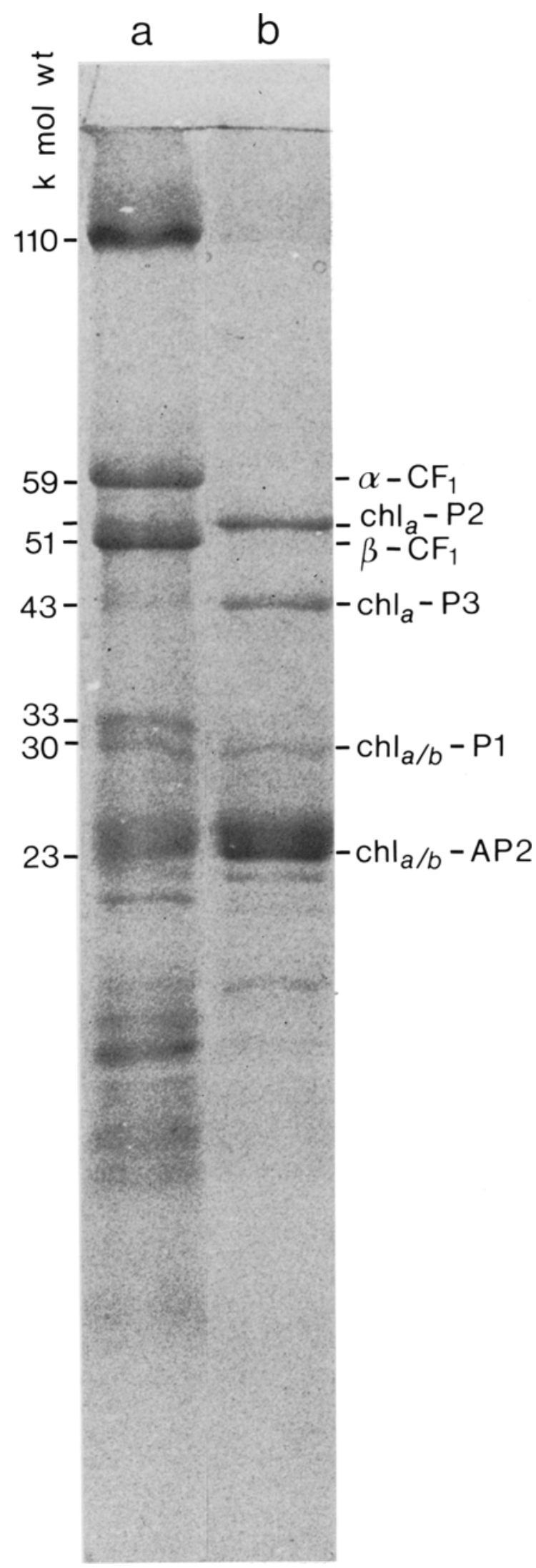




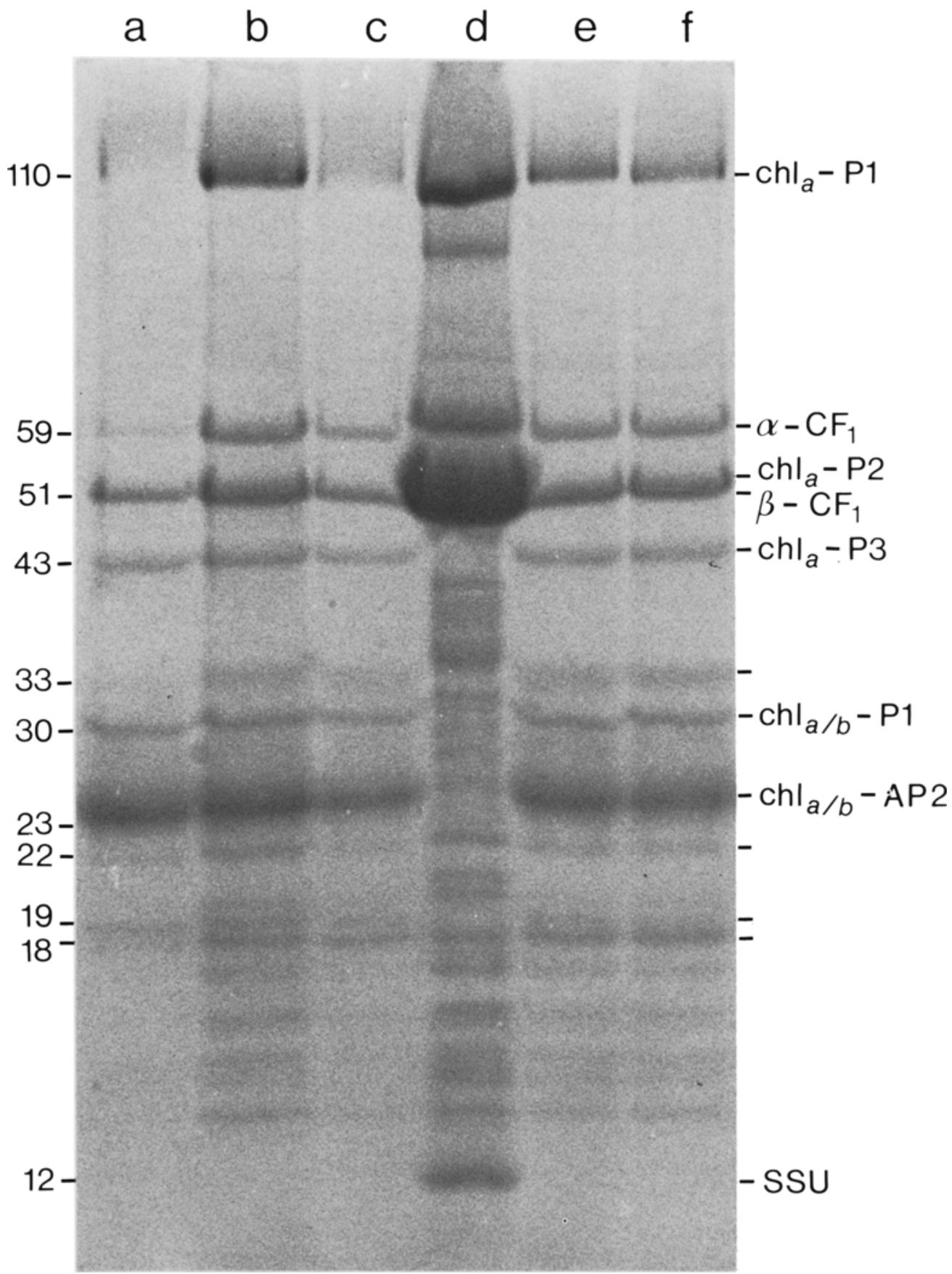

Figure 6. Polypeptide composition of the various fractions obtained during the preparation of photosystem II vesicles: $a=$ photosystem II vesicles; $b=$ vesicles partitioning to the polyethylene glycol phase; $c=$ disrupted grana; $d=$ stroma lamellae; $e=$ grana; $f=$ thylakoids .

Electrophoretic conditions as indicated in legend to Figure 4. SSU: small subunit of Ribulose-1,5bisphosphate carboxylase. 
The polypeptide composition of all the various fractions obtained during isolation of the PS II particles are compared in Figure 6. The intensity of the Coomassie Blue stained $\mathrm{Chl}_{\alpha}-\mathrm{Pl}$ in the different fractions agrees well with that of the corresponding chlorophyll band (Figure 4A). $\mathrm{Chl}_{\alpha}$-P2 migrates with an apparent molecular weight of 51,000 (Figure 6). The large subunit of ribulose-1,5-bisphosphate carboxylase and the $\beta$ subunit of chloroplast coupling factor $\left(\mathrm{CF}_{1}\right)$ have similar mobility. The simultaneous occurrence of the two heavy bands with molecular weights of 51,000 and 12,000 in track d of Figure 6 are thought to represent the large and small subunit of ribulose-1,5-bisphosphate carboxylase. Studies (25) on $\mathrm{CF}_{1}$ isolated from spinach and barley chloroplasts have shown similar staining intensities of the $\alpha$ - and $\beta$-subunits. Thus the contribution of the $\beta$-subunit to the staining intensity observed in the 51,000 region can be assessed from the staining intensity of the $\alpha$ subunit at 59,000 . Such a comparison shows that $\mathrm{CF}_{1}$ is absent (Figure 5) or present in very low amounts (Figure 6) in the PS II vesicles. In contrast, the presence of $\mathrm{CF}_{1}$ in the remaining fractions is evident from the strong staining of the $\alpha$-subunit at 59,000 . This is also supported by the absence of chlorophyll bands in the 51,000 region in these fractions. The Coomassie Blue bands at 43,000 and 30,000 are located at the positions of $\mathrm{Chl}_{a}-\mathrm{P} 3$ and $\mathrm{Chl}_{a / b}-\mathrm{Pl}$, respectively, and are enriched in the PS II vesicles compared to stroma lamellae. A polypeptide band corresponding to the apoprotein of $\mathrm{Chl}_{\alpha / b^{-}}$. $\mathrm{P} 2$ is seen in all the fractions except stroma lamellae. In addition to the four chlorophyll proteins described above, the PS II vesicles contain four polypeptides of unknown function. These all stain weakly with Coomassie Blue and the two with molecular weights of 33,000 and 18,000 may be the same components as those which are stained with tetramethylbenzidine (Figure 4C).

\section{DISCUSSION}

A photosystem II vesicle with retained capacity of oxygen evolution has been isolated from spinach chloroplasts using the aqueous twophase separation of membrane vesicles developed by Albertsson $(1,2)$. The vesicle showed high rates of oxygen evolution with PS II electron acceptors, little PS I activity, an enrichment in cytochrome $b$-559HP, a depletion of cytochrome $b-563$, reversed proton pumping, a low F735/ F695 ratio and a simple polypeptide composition. Addition of DCMU (Figure 3) or Tris washing $(0.8 \mathrm{M}, \mathrm{pH} \quad 8.8)$ abolished oxygen evolution and proton gradient formation.

PS II vesicles of varying purity have been isolated from algae, cyanobacteria and higher plants but these have all been inactive with respect to $\mathrm{H}_{2} \mathrm{O}$-splitting activity $(10,30,39)$. Their photochemical characterization was therefore based on measurements using the artificial electron donor diphenylcarbazide. Recently, a PS II particle capable of $\mathrm{H}_{2} \mathrm{O}$-splitting has been isolated from the thermophilic cyanobacterium Phormidium laminosum (43). In contrast to the spinach vesicle it was more complex with respect to cytochrome content and polypeptide composition.

The cytochrome content of the PS II vesicle herein reported is in agreement with earlier fractionation studies indicating a non-uniform distribution of the cytochromes. Although the exact localization of cytochrome $b-563$ $\left(\mathrm{E}_{\mathrm{m}}-110 \mathrm{mV}\right)$ and cytochrome $b$-559LP $\left(\mathrm{E}_{\mathrm{m}}+20 \mathrm{mV}\right)$ is unknown, they are thought to function in cyclic electron flow around PS I and II, respectively $(17,20)$. Cytochrome $f$ $\left(\mathrm{E}_{\mathrm{m}}+375 \mathrm{mV}\right)$ is associated with PS I (17) and cytochrome $b-559 \mathrm{HP}\left(\mathrm{E}_{\mathrm{m}}+380 \mathrm{mV}\right)$ is thought to be closely involved on the oxidising side of PS II (23). Ageing of the chloroplasts is accompanied by the conversion of cytochrome $b-559 \mathrm{HP}$ to a form of lower potential $(23,38)$ and could have resulted in an over-estimation of cytochrome $b$-559LP present in the PS II particle.

The reversed proton pumping of vesicles partitioning to the dextran-rich lower phase upon phase-partitioning was earlier demonstrated by ANDERsson, ÁkerLund and Albertsson (4). The PS II vesicles in the present study obtained have the same characteristics and thus appear to have been derived from grana stacks in accordance with the proposed mechanisms $(5,7)$.

The low temperature fluorescence emission spectrum of the PS II vesicles contained a principal peak at $695 \mathrm{~nm}$. One molecular species which emits at this particular wavelength is thought to belong to the antenna of the PS II 
reaction center. In accordance, an increased emission at this wavelength could be expected in a PS II vesicle. A blue shift of this component was observed in PS II particles studied earlier and has been attributed to an alteration in the molecular environment of the F695 component. The emission spectrum of the stroma lamellae was confined to one peak at $731 \mathrm{~nm}$. It has thus been possible to separate the short and long wavelength components of the composite emission spectrum of the chloroplasts without alteration of the fluorescence patterns.

The properties of the PS II vesicle described above are identical with those properties of freshly isolated chloroplasts which have been attributed to PS II. Retention of these characteristics appears to be related to the omission of detergents during its preparation. For instance, loss of the $\mathrm{H}_{2} \mathrm{O}$-splitting activity (47), alteration in certain spectral characteristics (26) and an alteration of the redox potential of cytochrome $b$-559HP (38) are seen upon addition of the comparatively mild non-ionic detergent Triton $\mathrm{X}-100$ to isolated chloroplasts. Furthermore, a direct correlation between amount of PS II $\mathrm{H}_{2} \mathrm{O}$ splitting activity and the $E_{m}$ of cytochrome $b$-559HP has been demonstrated (23). This correlation is supported by the present data.

Sodium dodecylsulfate polyacrylamide gel electrophoresis under relatively mild conditions (31) revealed the presence of four chlorophyllproteins in the PS II particle. These have been identified as $\mathrm{Chl}_{a}-\mathrm{P} 2, \mathrm{Chl}_{a}-\mathrm{P} 3, \mathrm{Chl}_{a / b}-\mathrm{Pl}$ and $\mathrm{Ch}_{a / b}-\mathrm{P} 2$. All these chlorophyll-proteins have earlier been assigned to PS II by the use of photosynthetic mutants and by fractionation studies (31). The identity of the four remaining polypeptides is unknown although two of these appear to stain with tetramethylbenzidine. The weak staining intensity of these polypeptides with Coomassie Blue could indicate a weak staining affinity or their presence in less than stoichiometric amounts compared to the chlorophyll-proteins. One of these polypeptides has an apparent molecular weight in the region of 32,000 . Since the photosystem II vesicles are sensitive to DCMU, this polypeptide could be the shielding protein which binds DCMU (32). A manganese-containing protein involved in oxygen evolution has been isolated from spinach chloroplasts (42). This protein has a molecular weight of 65,000 and should be contained in the PS II particle but could not yet be set in relation with certainty to any of the observed polypeptide bands. Photochemical measurements also indicate the presence of high amounts of cytochrome $b-559 \mathrm{HP}$ in the vesicle. This cytochrome has been reported to be composed of subunit polypeptides with molecular weights around 6,000 (49). It has also not been possible to assign a specific polypeptide band of the PS II particle to this cytochrome. Photosystem II membranes isolated from a mutant of Chlamydomonas (19) deficient in coupling factor and PS I show the presence of $\mathrm{Ch}_{a}-\mathrm{P} 2$ and $\mathrm{Chl}_{a}-\mathrm{P} 3$ in addition to several other unidentified components. Since they show similar electrophoretic mobilities, these two chlorophyll-proteins may also be regarded as identic with components of a PS II particle recently isolated from the cyanobacterium Anacystis nidulans (30).

Although the procedure of phase-partitioning was previously used to isolate inside-out membrane vesicles from chloroplast grana (4-6), electrophoretic analyses showed that such vesicles contained polypeptides attributable to both photosystems. In these earlier analyses, the procedure was directed towards the isolation of vesicles of opposite sidedness whereas the goal of the present study was to obtain a PS II vesicle with no PS I contamination. One possibility is that these PS II vesicles are derived more strictly from the appressed regions of the granal stacks. This would be in agreement with the suggestion of the exclusive location of PS II components together with the light-harvesting chlorophyll $a / b$-protein in the appressed regions $(8,9)$. Alternatively, the detergent-like properties of polyethylene glycol $(29,46)$ in the higher concentrations used may have resulted in the extraction of PS I components from the membrane vesicles in the bottom phase and their partitioning into the upper phase.

\section{ACKNOWLEDGEMENTS}

We are indebted to Professor Per-Åke ALBertsSON, Dr. Bertil ANDERSSON, Dr. HansErik Åkerlund and Ms. Cecilia Sundby, Department of Biochemistry, University of Lund, Sweden, for kindly introducing us to the technique of phase separations during visits to 
their laboratory. Professor D. von WetrsteIn is thanked for encouragement throughout this work. Bent Hansen, Inga Olsen, and ANN-Sofi STEINHOLZ are thanked for technical assistance. This work was supported by a long-term EMBO fellowship to L. E. A. Henry and by the Commission of European Communities, contract No. ESD-013-DK(G) of the Solar Energy Program.

\section{REFERENCES}

1. AlbertsSon, P.-Å.: Separation of particles and macromolecules by phase partition. Endeavour 1, 69-74 (1977)

2. Albertsson, P.-Å.: Partition between polymer phases. J. Chromatogr. 159, 111-122 (1978)

3. Andersson, B., H.-E. Åkerlund \& P.-Å. AlBERTSSON: Separation of subchloroplast membrane particles by counter-current distribution. Biochim. Biophys. Acta 423, 122-132 (1976)

4. Andersson, B., H.-E. Åkerlund \& P.-Å. AlBERTSSON: Light-induced reversible proton extrusion by spinach-chloroplast photosystem II vesicles isolated by phase partition. FEBS Lett. 77, 141-145 (1977)

5. Andersson, B., D. J. Simpson \& G. HoyerHANSEN: Freeze-fracture evidence for the isolation of inside-out spinach thylakoid vesicles. Carlsberg Res. Commun. 43, 77-89 (1978)

6. Andersson, B. \& H.-E. ÅkerLund: Inside-out membrane vesicles isolated from spinach thylakoids. Biochim. Biophys. Acta 503, 462-472 (1978)

7. Andersson, B., C. Sundby \& P.-Å. Albertsson: A mechanism for the formation of inside-out membrane vesicles. Preparation of inside-out vesicles from membrane-paired randomized chloroplast lamellae. Biochim. Biophys. Acta $599,391-402(1980)$

8. Andersson, B. \& J. M. Anderson: Lateral heterogeneity in the distribution of chlorophyllprotein complexes of the thylakoid membranes of spinach chloroplasts. Biochim. Biophys. Acta $593,427-440$ (1980)

9. Anderson, J. M.: Consequences of spatial separation of photosystem 1 and 2 in the thylakoid membranes of higher plant chloroplasts. FEBS Lett. 124, 1-10 (1981)

10. Apel, K., L. Bogorad \& C. L. F. Woodcock: Chloroplast membranes of the green alga Acetabularia mediterranea. Biochim. Biophys. Acta 387, 568-579 (1975)

11. Arnon, D. I.: Copper enzymes in isolated chloroplasts. Polyphenoloxidase in Beta vulgaris. Plant Physiol. 24, 1-14 (1949)

12. Bendall, D. S., H. E. Davenport \& R. Hill: Cytochrome components in chloroplasts of the higher plants. Method Enzymol. 23, 327-344 (1971)

13. Bengis, C. \& N. Nelson: Subunit structure of chloroplast photosystem I reaction center. J. Biol. Chem. 252, 4564-4569 (1977)

14. Butler, W. L.: Energy distribution in the photochemical apparatus of photosynthesis. Ann. Rev. Plant Physiol. 29, 345-378 (1978)

15. Chua, N.-H. \& P. Bennoun: Thylakoid membrane polypeptides of Chlamydomonas reinhardtii. Wild type and mutant strains deficient in photosystem II reaction center. Proc. Nat. Acad. Sci. USA 72, 2175-2179 (1975)

16. Clayton, R. K. \& R. Haselkorn: Protein components of bacterial photosynthetic membranes. J. Mol. Biol. 68, 97-105 (1972)

17. Cramer, W. A.: Cytochromes. In: Enzyclopedia of Plant Physiology, New Series volume 5 (A. Trebst \& M. Avron eds.). Springer-Verlag, Berlin, Heidelberg. New York, pp. 227-237 (1977)

18. Diner, B. A. \& P. Joliot: Oxygen evolution and manganese. In: Encyclopedia of Plant Physiology, New Series volume 5 (A. Trebst \& M. Avron eds.). Springer-Verlag, Berlin, Heidelberg, New York, pp. 187-205 (1977)

19. Diner, B. A. \& F.-A. Wollman: Isolation of highly active photosystem II particles from a mutant of Chlamydomonas reinhardii. Eur. $\mathbf{J}$. Biochem, 110, 521-526 (1980)

20. Heber, U., N. K. Boardman \& J. M. Anderson: Cytochrome b563 redox changes in intact $\mathrm{CO}_{2-}$ fixing spinach chloroplasts and in developing pea chloroplasts. Biochim. Biophys. Acta 423, 275292 (1976)

21. Henry, L. E. A. \& P. A. Siegenthaler: Does the intitial state of thylakoids influence photochemical activities, lipid transformations and the characteristics of the chlorophyll complexes? In: Proc. Int. Congr. Photosynth. 5th, G. Akoyunoglou ed., in press (1981)

22. Hiller, R. G., B. L. Møller \& G. HøyerHANSEN: Characterization of six putative photosystem I mutants in barley. Carlsberg Res. Commun. 45, 315-328 (1980)

23. Horton, P. \& E. Croze: The relationship between the activity of chloroplast photosystem II and the midpoint oxidation-reduction potential of cytochrome b-559. Biochim. Biophys. Acta 462, 86-10! (1977)

24. Høyer-HANSEN, G.: Identification of haemproteins in thylakoid polypeptide patterns of 
barley. Carlsberg Res. Commun. 45, 167-176 (1980)

25. Høyer-Hansen, G., B. L. Møller \& L. C. Pan: Identification of coupling factor subunits in thylakoid polypeptide patterns of wild-type and mutant barley thylakoids using crossed immunoelectrophoresis. Carisberg Res. Commun. 44. 337-351 (1979)

26. Il'ina, M. D., E. A. Kotora \& A. Yu. Borisov: The detergent and salt effect on the lightharvesting chlorophyll $a / b$ complex from green plants. Biochim. Biophys. Acta 636. 193-200 (1981)

27. JUNGE, W.: Physical aspects of light harvesting, electron transport and electrochemical potential generation in photosynthesis of green plants. In: Encyclopedia of Plant Physiology, New Series, volume 5 (A. Trebst \& M. Avron eds.). SpringerVerlag, Berlin, Heidelberg, New York, pp. 5993 (1977)

28. KahN, A. \& D. von WetTstein: Macromolecular physiology of plastids. II. Structure of isolated spinach chloroplasts. J. Ultrastructural Research 5, 557-574 (1961)

29. KaO, K. N. \& M. R. Michayluk: A method for high frequency intergeneric fusion of plant protoplasts. Planta 115, 355-367 (1974)

30. KoEnig, F. \& L. P. Vernon: Which polypeptides are characteristic for photosystem II? Analysis of active photosystem II particles from the bluegreen alga Anacystis nidulans. Z. Naturforsch. 36c, 295-304 (1981)

31. Machold, O., D. J. Simpson \& B. L. Møiller: Chlorophyll-proteins of thylakoids from wildtype and mutants of barley (Hordeum vulgare L.). Carlsberg Res. Commun. 44, 235-254 (1979)

32. Mattoo, A. K., U. Pick, H. Hoffman-Falk \& M. Edelman: The rapidly metabolized 32,000dalton polypeptide of the chloroplast is the "proteinaceous shield" regulating photosystem II electron transport and mediating diuron herbicide sensitivity. Proc. Natl. Acad. Sci. USA 78, 1572-1576 (1981)

33. Møller, B. L., R. M. Smillie \& G. HøyerHANSEN: A photosystem I mutant in barley (Hordeum vulgare L.). Carlsberg Res. Commun. 45 , 87-99 (1980)

34. Møller, B. L., G. Høyer-Hansen \& R. G. HILLER: Functional identification of barley thylakoid polypeptides resolved by SDS-polyacrylamide gel electrophoresis. In: Proc. Int. Congr. Photosynth. 5th, G. Akaoyunoglou ed., in press (1981)

35. NeumanN, J. \& A. T. JaGendorf: Light-induced $\mathrm{pH}$ changes related to phosphorylation by chloroplasts. Arch. Biochem. Biophys. 107, 109-119 (1964)

36. Peterson, G. L.: A simplification of the protein assay method of Lowry et al. which is more generally applicable. Anal. Biochem. 83, 346356 (1977)

37. Rich, P. R.: Quinol oxidation in Arum maculatum mitochondria and its application to the assay, solubilization and partial purification of the alternate oxidase. FEBS Lett. 96, 252-256 (1978)

38. Rich. P. R. \& D. S. Bendall: The redox potentials of the b-type cytochromes of higher plant chloroplasts. Biochim. Biophys. Acta 591, 153-161 (1980)

39. Sатон, K. \& W. L. Butler: Low temperature spectral properties of subchloroplast fractions purified from spinach. Plant Physiol. 61, 373379 (1978)

40. Simpson. D., G. Høyer-Hansen, N.-H. Chua \& D. voN WETTSTEIN: The use of gene mutants in barley to correlate thylakoid polypeptide components with the structure of the photosynthetic membrane. In: Proc. Int. Congr. Photosynth. 4th (D. O. Hall, J. Coombs \& T. W. Goodwin eds.). Biochemical Society. England, pp. 537-548 (1977)

41. Simpson, D. J. \& D. von Wettstein: Macromolecular physiology of plastids XIV. Viridis mutants in barley: Genetic, fluoroscopic and ultrastructural characterisation. Carlsberg Res. Commun. 45, 283-314 (1980)

42. Spector, M. \& G. D. Winget: Purification of a manganese-containing protein involved in photosynthetic oxygen evolution and its use in reconstituting an active membrane. Proc. Natl. Acad. Sci. USA 77, 957-959 (1980)

43. Stewart, A. C. \& D. S. Bendall: Properties of oxygen-evolving photosystem II particles from Phormidium laminosum, a thermophilic blue. green alga. Biochem. J. 194, 877-887 (1981)

44. Thomas, P. E., D. Ryan \& W. Levin: An improved staining procedure for the detection of the peroxidase activity of cytochrome P-450 on sodium dodecyl sulfate polyacrylamide gels. Anal. Biochem. 75, 168-176 (1976)

45. Trebst, A. \& S. Reimer: Properties of photoreductions by photosystem II in isolated chloroplasts. Biochim. Biophys. Acta 305, 129-139 (1973)

46. WaLLiN, A. \& T. ERIKSSON: Induction of aggregation and fusion of Daucus corota protoplasts by polyethylene glycol. Z. Pflanzenphysiol. 74, 64-80 (1974)

47. Wessels, J. S. C.: Fragmentation. In: Encyclopedia of Plant Physiology, New Series, volume 5 
(A. Trebst \& M. Avron, eds.). Springer-Verlag, Berlin, Heidelberg, New York, pp. 563-573 (1977)

48. Wettstein, D. von: Chloroplast and nucleus: Concerted interplay between genomes of different cell organelles. In: Internat. Cell Biol. 19801981 (H. G. Schweiger ed.). Springer-Verlag, Berlin, Heidelberg, New York, pp. 250-272 (1981)

49. Zielinski, R. E. \& C. A. Price: Synthesis of thylakoid membrane proteins by chloroplasts isolated from spinach. Cytochrome b-559 and P700-chlorophyll a-protein. J. Cell Biol. 85, 435-440 (1980)

50. Ákerlund, H.-E., B. Andersson \& P.-À. Albertsson: Isolation of photosystem II enriched membrane vesicles from spinach chloroplasts by phase partition. Biochim. Biophys. Acta $449,525-535(1976)$ 